\title{
Building Innovation Competencies
}

\author{
Charles Bezerra, Ph.D. \\ University of Otago, New Zealand \\ charles.bezerra@design.otago.ac.nz
}

\begin{abstract}
This research explores the issues concerning innovation education. What essential knowledge and attitudes facilitates the emergence of innovative concepts? How can innovation competencies be learned or taught? What are the appropriate methods or tools for a discipline of innovation? This research is targeted at creating a program of study that combines the best approaches and practices in building innovation competencies, so students can become leaders capable of influence any business or technology. The methods and experiences of the strategic design program at the University of Otago, New Zealand, will be described.
\end{abstract}

\section{Introduction}

As our world becomes more and more connected; our markets more dynamic and competitive; and our technology more changeable; organizations are in urgent need for those capable of creating viable new concepts. Innovation competencies are being required in all fields and at all levels. From individuals to organizations, innovation competence means advantage.

Innovation is not only the act of introducing something new, but it is to introduce something new that becomes widely adopted. A very challenging task, but well rewarded in open markets.

In today's competitive economic context, which demands innovation, one cannot depend or accept only the idea that innovative concepts come exclusively from 'gifted' people, or that innovation is an intellectual 'accident' of inspiration and not the result of hard and focused work [1].

Although one cannot guarantee that a given concept will end up a business success, there are conditions, knowledge and attitudes that can facilitate the emergence of innovative ideas. The innovation discipline is still in its infancy, but competencies that increase the chances of innovation can now be learned.

The following involves a discussion on the discipline of innovation and a description of the principles used in the strategic design program at the University of Otago.

\section{A Discipline without Borders}

Although innovation is becoming a very popular topic no particular area of knowledge owns the discipline of innovation. Innovation requires multidisciplinary perspectives.

Innovation experts are not necessarily experts in any specific product or area, but are expert in processes of designing, which mainly involves competence in the activities of problem-solving as well as problemfinding.

According to Popper [2], we are students not of disciplines but of problems. And this is extremely true in the case of innovation attempts. Innovation problems involve an exploration of three main questions: first, the question of what is desirable by the customer/market? Second, what is doable with the available technology? And third, what is profitable for the business?

Innovation can assume different forms (it can be a new product, system, process, message, environment, software, or service, to name a few); but so far it begins only in one place - our minds. Innovative solutions are condensed information. It is the result of a complex cognitive ability, and therefore, influenced by knowledge as well as attitudes. For example, it requires strategic and systemic thinking as well as patience and self-motivation.

Specialization can be seen as a mortal sin for the real innovator. Innovators are specialized generalists; their success comes from their ability for seeing connections. Innovation requires a balanced intellectual attitude that also involves: the ability to avoid excessively broad or narrow generalizations, or confusion from cross-coupling; the ability to acknowledge mistakes and un-productive paths; and the ability to discard useless information. 
In a way, the basic mechanisms of evolution, discovered by Darwin (mutation, crossover and selection), can offer useful insights for the discipline of innovation. Innovative ideas are also the result of an evolutionary process [3], which includes changes (mutation), associations (crossover), and filtering (selection).

\section{Innovation Education}

Innovation is a new discipline born from the understanding and application of methods from several different areas, such as, design, business and social sciences. As a discipline, innovation should help students to understand a context, assess the existing needs, envision opportunities for change and prescribe viable solutions. There are many conditions, knowledge and attitudes that have direct impact on building innovation competencies. Some key elements for an efficient innovation program of study are:

- Critical Discussion (condition) - To engage in critical discussion, is probably the first thing the innovation students should learn. The goal is to learn through criticism, from others, and also from self-criticism [4]. To learn from mistakes; learn to correct mistakes and improve their concepts. Dogmatic thinking blocks any process of innovation. When students are used to critical discussion they will realize that they or anyone else possesses the truth; and that everyone is capable of achieving innovative ideas. Therefore, in the discipline of innovation there are no too-silly or too-obvious questions. Critical thinking is key to build innovation competence, students have to learn how to value criticism, not avoid it. And this can be easily done trough teamwork activities and presentations where critical debate is encouraged.

- Strategic Focus (knowledge) - To think strategically is also a crucial competence in the discipline of innovation. It is hard to explain what strategically or strategy really means, but the main idea is to help students to look for the 'big picture' when they are asked to innovate. It is about helping them to take a distant perspective on what is close, and to take a close view on what is distant. It also involves thinking in terms of goals and the resources to achieve these goals. But above all, innovation strategy means planning the designing process; planning the activities and actions necessary to understand and solve the innovative problem.
Strategic thinking can be introduced through several class exercises involving games and student competitions; and developed through research, analytical and creative activities that reflect a general process of innovation.

- Dependence on Methods (knowledge + attitude) For the discipline of innovation, methods, processes and tools are fundamental. Students should learn to trust in their methods and techniques. They might not know anything about a particular problem, but they know that after applying their process of research and analysis, they will be able to generate innovative solutions. They should not believe they are especially creative, but that they have a toolbox (frameworks, methods, techniques) that enables them to make innovative interventions. In a sense, students of the innovation discipline should see themselves as batman-like super heroes, for much of their power comes from their utility-belt. Therefore, the innovative program should focus in mastering students in methods and techniques of research, analysis and synthesis.

- Human-Centered Approach (knowledge + attitude) - It is now very clear that most powerful innovations, the ones that become widely adopted, are those in which the focus of the process is not centered on the technology, or on the market, or still on the designer, but are those, which are centered on the end users. In a human-centered process, the question for whom we design comes first; than the question what we design comes second; and for last, comes the question of how we will implement it. The innovation students should learn that the success of their innovation is directly associated with the value it brings for peoples' lives. Therefore, a successful program of study should include techniques for accessing people' needs. Innovation students should believe they can change the world and improve peoples' lives, they should think humanity is their main customer. More than ever, we need innovations that can help us to fix some problems in our man-perturbed world.

\section{A Program of Study}

The goal of the Strategic Design program at the University of Otago is to help students to build innovation competencies, so they can efficiently cross the gap between need and offer in any business 
situation. Helping them to make a difference by developing their capability of integrating the business, technology and customers factors into systems that complement one another. More specific objectives include:

- To learn to think strategically through theory and methods.

- To develop a macro perspective on a specific business context.

- To research and understand quantitative and qualitative information

- To understand market/consumer/user needs

- To explore opportunities for developing breakthrough products, systems or services.

- To learn from successful business-cases from different markets

- To perform well in the initial/strategic phase of any product development process

The program of study consists of lectures (theory, reading and debate) and tutorial or seminars (project). The theory introduces diverse topics such as, strategic planning; game and complexity theory; and seeks to cover logical, ethical and rhetorical aspects of innovation. Logical in the sense it utilizes methods and rationale for problem-finding and problem-solving. Ethical because it encourages debate about the innovator' responsibilities towards the others and the environment. And, rhetorical because if develops communication and presentation skills.

Concerning their project, students have two main possibilities for choosing a topic: first, the option of developing an innovation plan for an existing business. Second, is the option of working in an innovation plan for a new business concept.

The expected output is a Strategic Design Plan - an extensive report that understands a specific business context; explores opportunities for innovation; and presents a plan for implementation that will position the proposed business ahead of competition.

All this is achievable because of a higher-level innovation framework based on specific methods and techniques. As students become familiar with the general structure of the framework, which fundamentally focuses on research, they are capable of positioning themselves in the process, thinking more strategically and, reflecting their understanding and creative vision about their topic.

\section{A Methodological Framework}

The utilized framework is very simple and it attempts to give a general structure for the phases that happens in the understanding and innovating processes
(Figure 1). Its goal is to show the flow and processing of information during innovation. Specifically, how information is transformed into knowledge, how knowledge is transformed into strategic advantage and how strategies are transformed into offers.

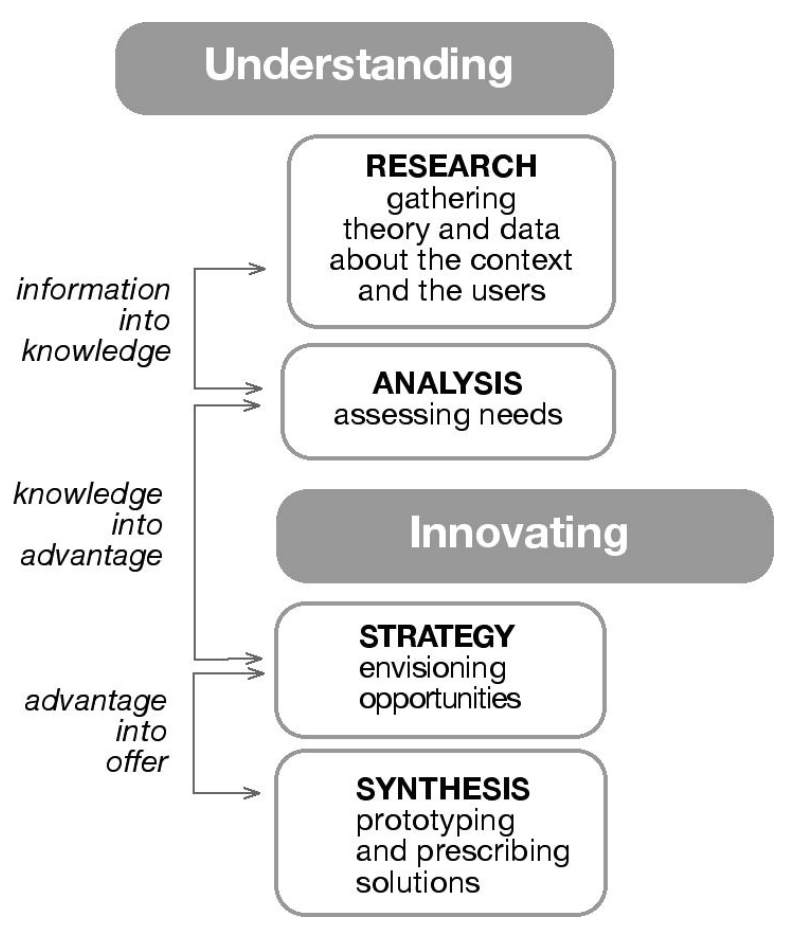

Figure 1. Development framework

Fundamentally, the processes of understanding involves activities of research and analysis. The goal of research is to collect different forms of information, quantitative and qualitative, about the context and its users.

\subsection{Research}

Research is a key for innovation. One might even think that creativity without research (information gathering) is impossible. Therefore, innovation students should be educated to become excellent researchers. Several universities have incorporated active research programs into their design and planning methodologies [5].

Students should be able to research theories and data related to their topic, and their research should be targeted at:

- Looking backwards - to have a historical perspective in their project, and also to detect trends.

- Looking sideways - to know what else is happening in parallel to their project, so they can have a broad perspective and to identify 
the direct and indirect forces that affect their topic.

- Looking at people - to know the end user, to capture problems, needs and desires; to have a clear idea for whom they are attempting to innovate [6].

- Looking ahead - to speculate about future scenarios and explore the possible opportunities.

In the research phase students engage in primary and secondary research to collect theories and data related to their projects. They are oriented to start four fundamental research activities: user-research (observations targeted at understanding their end-user); technology research (targeted at understanding the means and technological resources related to their projects); market-research (oriented to have a picture of the market their project is directed towards); and social and cultural research (targeted at understanding the social and cultural forces that affect their topic, from a local and global perspective).

Several ethnographic techniques are used to conduct user-observation. The main are:

- Video/photo ethnography - consists of video tapping or photographing specifics activities in the user's life.

- Disposable camera studies - consists of giving disposable camera to users and asking them to photograph specific events of their daily activities.

- Material culture studies - consists of registering and cataloguing the artefacts and objects the users are constantly interacting.

- In-depth interviews - informally interviewing the user in their environment.

- Shadowing - involves following a user for some hours recording what happens.

- AEIOU - an easy-to-remember observation framework which oriented to observing and collecting data concerned with: A - the activities (what the users are doing?); $\mathrm{E}-$ the environments (where? how is the space?); I - the interactions (interacting with whom? how?); $\mathrm{O}$ - the objects (using what objects and tools?); and U- the users (who are them?).

Clearly, the choice of what observation technique students will utilize in their research depends mainly on their topic. The important point for the innovation student is to recognize the need for user-observation, recognize that they cannot know the user's needs or desire without observing and understanding them.

A big confusion the innovation educator should clarify is that the goal for doing user-observation research is not to find the solutions or answers, but to understand the context, problems and needs of the users. Students should do user-research not expecting the user will be able to say all their needs and expectations, sometimes users' don't realize they behave in a certain way. Also, the innovation students should be aware that self-reporting is often flawed.

\subsection{Analysis}

Efficient research usually generates an enormous amount of information, which must be carefully analysed. The goal of the analysis phase is to gain and frame insights about the context and its agents, connecting, combining and making sense of the collected information. Therefore, activities such as listing, organizing, clustering, filtering and visualizing the information are the essence of analysis. It is on the analysis phase that data is transformed into knowledge, which involves seeing from a higher perspective to identify the patterns and access the needs. Depending on their project, students are advised to apply several analytical techniques:

- Profiles - attempt to create a profile of the main users of the system under consideration.

- System decomposition - break down the elements and agents of the project. Concept maps are excellent tools for this task.

- Social/Activity Network analysis - using social network principles to build sociograms (diagrammatic representation) of interactions of people and activities.

- Technology forecasting - looking for the past and present of technology to identify elements that could give support to speculations about future trends.

- Social/Cultural trends - looking for social/cultural indicators that could support conjectures about the future scenarios.

- Positioning maps - mapping the main offerings of the market to visually compare and clarify differences.

\subsection{Strategy}

Strategy is the first phase of the innovating dimension. In this phase students are oriented to focus on exploratory, creative and problem-solving activities. In the strategic phase, insights are transformed in strategies for solutions.

The goal is to envision the opportunities for innovation and develop the appropriated strategies for developing and implementing an offer. Opportunities are discovered based on the understanding achieved in the analytical phase. In fact, exploring and defining strategies are analytical activities, they happen after the information is organized, clustered and patterns are identified. General concepts from game theory are very useful at this stage; they help students to identify possibilities of differentiating their ideas. Main strategic techniques include:

- Opportunity exploration - involves conjecturing and mapping possible opportunities, trying to refute them 
to see which ones stands.

- Playing ahead - consists of identifying the behaviour of direct and indirect opponents (competition) and allies (collaborators) of the idea. Trying to conjecture their next possible business moves.

- SWOT - debate on the strengths, weakness, opportunities, and treats as they related to the specific idea.

- Strategy Definition - mainly involves deciding the strategy(s) to follow.

\subsection{Synthesis}

In the synthesis phase, strategies are transformed into ideas and concepts to be developed. The essence of synthesis is visualization, testing and communication of ideas. Examples of synthesis techniques are:

- Concept development - consists of moving from strategy to a representation of the concept.

- Scenario making - consists of visualizing concepts and user' experience scenarios.

- Prototyping - fundamental for the success of the project, consists of testing the proposed concept before they are fully developed. There are many levels of prototyping, depending on the project it can be more behavioural, cognitive, experiencial or physical.

- Implementation and change plan - consists basically of a road map for implementing the developed idea, as well as a plan for possible changes.

- Communication - also extremely important for the overall project, communicating the project is not an easy task, content, process and format have to be coherently orchestrated in a presentation. Innovation students have to be capable of efficiently deliver the project to different audiences.

Evidently, processes of innovations are not sequential as represented here, they involve many iterations and cycles between the phases of research, analysis, strategy and synthesis; however, it is important for the innovation student to have a framework to follow and to understand the value of the different tasks they will have to perform. Once the students understand the goal of these tasks they are able to create new tasks that are more oriented to their project, creating new tools for their toolbox.

At the University of Otago, the focus on research and strategy is improving the quality of the work on many students.

Because the process is structured and strategically driven they are capable of producing less candidate alternatives (quantity) and more innovative concepts (quality).

\section{Conclusion}

For the innovation discipline, there are only students, not teachers. Those responsible for supporting the development of innovation competencies know that all they can do is to introduce a structure, a process for gathering and using information. As suggested in this paper, innovation competencies involve competencies in research, analysis, strategy and synthesis.

Each attempt to innovate brings its own complexity. The difference between the novice and expert innovator is in their ability to use and create techniques appropriated to their needs. The confidence and security of the innovator comes from their belief in their process. They might not know about a particular problem in the beginning, but by applying some research methods and techniques they will not only be able to understand much about it - they will also be capable of proposing creative and feasible new solutions.

Innovation competencies, the ability to understand a context and to propose a meaningful and innovative change, is one of the most powerful abilities our human minds have. Much individual and group concentration will be necessary to effectively produce a large-scale change in our world, that could increase freedom and reduce the violence, misery and environmental damage. More than ever before, innovators are being asked to assume their leadership positions. More than ever before, logical and ethical innovation competencies are needed.

\section{References}

[1] P.F. Drucker, "The Discipline of Innovation", Harvard Business Review, August, 2002, pp.95-102.

[2] K. Popper, Conjectures and Refutations, Routledge Classics, New York, 2002.

[3] C. Bezerra and C. L. Owen, "Evolutionary Structured Planning", Artificial Intelligence in Design, Kluwer Academic Publishers, The Netherlands, 2000, pp. 287-307 [4] K. Popper, All Life is Problem Solving, Routledge, New York, 1999.

[5] P. Rothstein, "When worlds collide: Integrated development with business and design students", Design Management Journal, Summer 2002, pp. 62-69.

[6] D. Leonard and J. Rayport, "Spark Innovation Through Empathic Design", Harvard Business Review, NovemberDecember 1997, pp. 102-113. 